\title{
Update online-HDF
}

\author{
Thomas Ryzlewicz \\ Director, Medis Dialysis center, Germany
}

Received: October 2, 2016; Accepted: February 28,2017; Published: March 15, 2017

*Corresponding author: Thomas Ryzlewicz, Director, Medis Dialysis center, Germany.E-mail: thomas.ryzlewicz@web.de

In 1982 Schaefer had invited Shaldonfor a publication in Blood purification. In this paper, Shaldon developed the Interleukin-1Hypothesis. With this background, he realized 1983 in Montpelier the first prototypes of the (real) online-Hemofiltration, using 20 (!) high-flux ultra filters of polyamide. The name "online" means a 2-step treatment: The first step was the production of the later used infusate, the second step was the treatment of the patient (the today used set-up should better named "inline", as today there is no storage of the produced infusate). But the wrong name (online) had established for this treatment. One of Shaldons first co-workers of this project was Canaud. With the use of these real online-prototypes, the necessity of the numbers of the ultra filters had reduced at first to ten and later on to five within two years.

In 1993 the first prototypes of the combined treatment, the "inline"-Haemo-Diafiltration had presented, using three ultra filters. This is nearly the set-up of today. There are small variations; these will be discussed later on.

Additional to the classic (diffusive) treatment, the online-HDF uses high convective ultrafiltration (> solvent drag). By this way, larger amounts of bigger solutes (cut-off 25.000 Dalton) will also eliminated within the additional solved small molecules. Using this combined therapy, the realized $\mathrm{Kt} / \mathrm{V}$ is simply tidily higher as with diffusive treatment (dialysis) alone. The further big advantage of online-therapy is the requirement of sterile dialysis fluid. This had put down in the ISO norm 11663 (in 2009, updated in 2013). THIS means, that with the technique of the monitor and the mode of disinfection a SAL 6 is necessary to reach for production of infusion fluid (SAL 8 means a CFU reduction of the power 10 exponent minus 8). Simply spoken: You only can realize this only with a 2-step ultrafiltration.

When using online-HDF, there is the principle of filtration inside (> convective therapy). For this, a big high-flux (haemofilter, $2 \mathrm{~m}^{2}$ surface) should be used.

The mode of supply of the infusate (pre-dilution or postdilution?): Henderson had presented the bag hemofiltration in 1967 as pre-dilution (!), whenever the costs of the infusion bags were expensive (!). Ledebo had shown 1993 comparing hemofiltration in pre-dilution with the post-dilution mode, that there is a big difference of the blood flow to reach the same filtrated volumes: $400 \mathrm{cc} / \mathrm{min}$. in pre-dilution in comparison to
$700 \mathrm{cc} / \mathrm{min}$. in post-dilution. So it is much easier, to realize a blood flow of $400 \mathrm{cc} / \mathrm{min}$., isn't it? - When using the combined therapy (online-HDF), you will have the higher $K t / V$ with the predilution in comparison to the post-dilution with the same amount of litres. This context had nearly not well understood (!). The assessment of pro's and con's in between online-HDF pre-dilution and online-HDF post-dilution: The disadvantage of the reduction of the concentration difference in pre-dilution is smaller than the con's in post-dilution (lengthening of the way of diffusion because of packed cell volume in the venous half of the high-flux and the secondary protein membrane by the high TMP). Unfortunately, this had strongly neglected by the companies and by the opinion leaders, so the industry had developed the pressure driven mode to reach the higher convection with easy handling. This pressure driven mode of online-HDF post-dilution had updated to the auto-processing mode (in premium monitors).

With a premium monitor in auto-processing mode (> using post-dilution) you will reach with a $2 \mathrm{~m}^{2}$ high-flux a convection of $100 \mathrm{cc} / \mathrm{min}$. resp. 6,0 litre/hour, when using real blood flows of 350 to $400 \mathrm{cc} / \mathrm{min}$. This is nearly a practical limit. You only can overcome this limit with higher blood flow ( $>$ real blood flow of $450 \mathrm{ml} / \mathrm{min}$. with $14 \mathrm{G}$ tubules).

Using the pre-dilution mode, the requirement of the blood flow is not so important. With real blood flow of $350 \mathrm{cc} / \mathrm{min}$. you get good results, at first. Then, the requirement of the equipment is moderate: a standard monitor is sufficient (only in volume drive mode). At the end, you can enlarge the convective volume. 125 cc/min. (resp. 7, 5 litres/ hour) are easily to realize. The maximal convective rate may be in between 125 and $150 \mathrm{cc} / \mathrm{min}$. So this additional enlargement of the convective volume is the second reason for the superiority of the pre-dilution mode. - Naturally, the total dialysis flow should adapted to the higher flows of blood and of convection. So a higher total dialysis flow will be necessary to produce the optimal quality of online-HDF.

Sterile dialysis fluid and the disinfection: The books of pharmacy did not know the online production of infusion fluid. Shaldon had used formaldehyde and later on per-acetate (low per cent) as disinfection. Today, the common use of disinfection online monitors is hot citric disinfection. The monitors will made empty after this disinfection. The problem of this way of disinfection is that the ultra filters remain filled up with fluid 
and so there is growth of CFU's. This mode of disinfection does not fulfil the ISO norm 11663(!). The faith into the absorption capacities of the ultra filters is not enough! Regular CFU's testing seems reasonable to continue. I myself does continue the peracetate disinfection at online monitors.

The three studies: Canaud (very long experience with online therapy) stated in 2004, that there might be a good chance for longer survival of patients, when treated with onlineHDF (retrospective study). In 2012 and 2013 three prospective randomized studies with online-HDF had published. Target was the question, whether there is a proven longer survival, when patients had treated with online-HDF. The results are well known (CONTRAST study and Turkish study failed, ESHOL study had shown proven longer survival).

Critics of the three studies: All three studies used too short treatment time. The Turkish study had a very poor convective volume ( $>$ only standard monitors (volume mode), pre-dilution not used). CONTRAST and ESHOL had used premium monitors (> auto-processing so both had clearly higher convection). But higher blood flows, pre-dilution mode or enlargement of treatment time had not used in both studies. ESHOL was successful to prove longer survival with online-HDF post-dilution.

High-flux disposables had developed for convective therapy. The availability of volume mode driven dialysis monitors leaded to the high use of high-flux in the simple dialysis therapy, whenever two big studies (HEMO \& MPO, both prospective randomized, both with 5000 patients) were unable to show a longer survival in the high-flux group. There had been dark bacteriologic circumstances using high-flux without any ultra filter ( $>$ but this is finished today). Using the expectancy of Canaud and the ESHOL study, there is a proven longer survival for the patients treated with online therapy (whenever the treatment should be more intensified).

The situation in the US: A poor (short) treatment time is often used (economic and assurance aspects). US patients have higher body weights ( $>$ so they need by rights longer treatment times because of this). Then there is the re-use of dialyzers. All these three conditions will also run, when the online-HDF may started. With these US conditions of dialysis, it would be difficult to reach a better survival of the patients with online-HDF in the US. Only to enlarge the costs, this never can be the target.

The FDA Department of Medical Products: The admission of bag hemofiltration in the US had lasted 20 years (whenever it was an invention in the US!). Online-HDF has not approved by the FDA (since 23 years). There are several problems (fear of wrong handling, liability assurance, mode of disinfection, clear too short treatment time), they seems severe to overcome in the US.

\section{Conclusion}

It is up to the doctors (in the rest of the world), to decide the mode of dialysis treatment of his individual patient. In this, the life expectancy of the individual patient will be important. The mode of pre-dilution with enlarged convection $(125 \mathrm{cc} / \mathrm{min}$. or a little more) is the best option (> if necessary, enlargement of the dialysis flow). A new online-HDF study seems unlikely, as the majority of the opinion leaders had not understood the potential improvement inside the online-HDF set-up.

\section{References}

1. Blankestijn P. Has the time come now to more widely accept Hemodiafiltration in the US? JASN. 2013;24(30):332-334. doi: 10.1681/ASN.2013010063

2. Canaud B, Bragg-Gresham JL, Marshall MR, Desmeules S, Gillespie BW, Depner T, et al. Mortality risk for patients receiving Hemodiafiltration versus Hemodialysis: European results from the DOPPS. Kidney Int. 2006;69(11):2087-2093. doi: 10.1038/sj.ki.5000447

3. ISO norm 11663-2014, includes dialysis fluids used for haemodialysis and haemodiafiltration, including substitution fluid for haemodiafiltration and haemofiltration. 2014.

4. Ledebo I: online hemofiltration. Berlin Dialysis Seminar 1993, oral lecture.

5. Locatelli F, Marcelli D, Conte F, Limido A, Malberti F, Spotti D. Comparison of mortality in ESRD patients on convective and diffusive extracorporeal treatments, The Registro Lombardo Dialisi E Trapianto. Kidney Int. 1999;55(1):286-293. doi: 10.1046/j.15231755.1999 .00236

6. Francisco Maduell, Francesc Moreso, Mercedes Pons, Rosa Ramos, Josep Mora-Macià, Jordi Carreras, et al. High Efficiency Postdilution Online Hemofiltration Reduces All-Cause Mortality in Hemodialysis Patients. JASN. 2013;24(3):487-497. doi: 10.1681/ASN.2012080875

7. Ok E, Asci G, Toz H, Ok ES, Kircelli F, Yilmaz M, et al. Mortality and cardiovascular events in online haemodiafiltration (OL-HDF) compared with high-flux dialysis results from the Turkish OL-HDF Study. NDT. 2013;28(1):192-202. doi:10.1093/ndt/gfs407

8. Shaldon S, Beau MC, Deschodt G, Flavier JI, Nilson I, Ramperez P, et al. Three years of experience with online preparation of sterile pyrogen free infusate for hemofiltration. Contrib. Nephrol., Basel Karger. 1982;32:161-164. 